\title{
Gay Men and Lesbian Women with Molestation History: Impact on Sexual Orientation and Experience of Pleasure
}

\author{
Jessica Jones Steed and Donald I. Templer*
}

Alliant International University, Fresno, California, USA

\begin{abstract}
This research focused on the 101 (36.07\%) of 280 non-clinical questionnaire-surveyed gay men and lesbians who reported molestations prior to the age of 16 . The homosexually molested participants were more likely to say that the molestation had an impact on their sexual orientation than heterosexually molested participants. The perpetrator was described as homosexual in $94.49 \%$ of female homosexual molestations and in $80.0 \%$ of male homosexual molestations. The experience was reported as pleasurable by $88.9 \%$ of females molested by females, $88.2 \%$ of males molested by females, $72.0 \%$ of males molested by males, and $48.9 \%$ of females molested by males. The molestation was reported to authorities in only $14 \%$ of the cases. The reader is urged to use considerable caution in making cause and effect inferences.
\end{abstract}

Keywords: Homosexual, molestation, sexual orientation.

\section{INTRODUCTION}

The present study extends the research of Tomeo, Templer, Anderson, and Kotler [1]. They found that $56 \%$ of gay men in contrast to $7 \%$ of heterosexual men, and $22 \%$ of lesbian women in contrast to $1 \%$ of heterosexual women, had reported homosexual molestation. Previous research also reported a history of molestation in gay men and lesbians [2-6]. The Tomeo et al. [1] research went beyond the previous research in that they used specific criteria of molestation by requesting the gender and age of the perpetrator and by the determination of both current sexual preference and that before the molestation. They found that $32 \%$ of gay men and $38 \%$ of the lesbians reported they were not homosexual before the homosexual molestation.

The present study went beyond the Tomeo et al. [1] research in that it inquired about (1) the apparent sexual orientation of the perpetrator, (2) the impact of the molestation on sexual orientation, (3) whether the molestation was pleasurable, and (4) whether the molestation was reported to authorities. The present study used the same criteria of molestation of Tomeo et al. [1], that is, sexual contact under the age of 16 with a person at least 16 years old and at least 5 years older than the victim.

\section{MATERIALS AND METHODOLOGY}

\section{Participants}

The participants consisted of 280 non-clinical adults from gay, lesbian, and bisexual organizations in Central California. They ranged in age from 18 to 72 years, with a mean of 29.03 and a standard deviation of 9.94. In regard to ethnicity of the participants, 117 (41.8\%) were Caucasian/White, 87 (31.1\%) were African American/Black/African, 40 (14.3\%)

*Address correspondence to this author at the Alliant International University, Fresno, California, USA; Tel: (559)431-1886; Fax: (559)4311886; E-mail: donaldtempler@sbcglobal.net were Hispanic/Mexican/Latino/Spanish, 11 (3.9\%) were Asian, $1(0.4 \%)$ was Native American, $11(3.9 \%)$ were various combinations of the above, and $13(4.6 \%)$ did not specify. The sexual orientation was stated as being gay or lesbian for $150(53.6 \%)$ and $130(46.4 \%)$ bisexual of the participants. They consisted of $143(51.1 \%)$ females and 137 $(48.9 \%)$ males. The females ranged in age from 18 to 61 , with a mean of 29.93 and standard deviation of 10.30 . The males ranged in age from 18 to 72 , with a mean of 28.09 and standard deviation of 9.50 . Sixty-eight $(49.6 \%)$ of males reported being gay and $69(50.4 \%)$ reported being bisexual. Females reported $82(57.3 \%)$ being lesbians and $61(42.7 \%)$ being bisexual. Within both genders, the gay/lesbian and bisexual participants were classified together. This was (a) to increase the power of the design; (b) because the literature indicates many gay men and lesbians, as well as bisexual men and women, have likely engaged in heterosexual behavior at some time in their lives [6-10]; and c) because previous research with reasonable findings has used this combination $[5,6,9]$. Inspection of the data showed no salient differences within gender related to gay/lesbian and bisexual participants. The criterion of sexual contact before 16 years of age with a person 16 years or older and at least 5 years older was met by $101(36.07 \%)$ participants.

\section{Instrument}

Table 1 displays the questionnaire administered to all participants. It was essentially the questionnaire used by Tomeo et al. [1], with the addition of questions pertaining to pleasure, impact on sexual orientation, sexual orientation of the perpetrator, and reporting to authorities.

\section{Procedure}

The principal investigator contacted directors of several Central California gay/lesbian organizations to obtain permission to distribute questionnaires to individuals 18 years of age or older in their organization. The consent and questionnaire were reviewed by individuals at the organization 
Table 1. Questionnaire Completed by All Participants

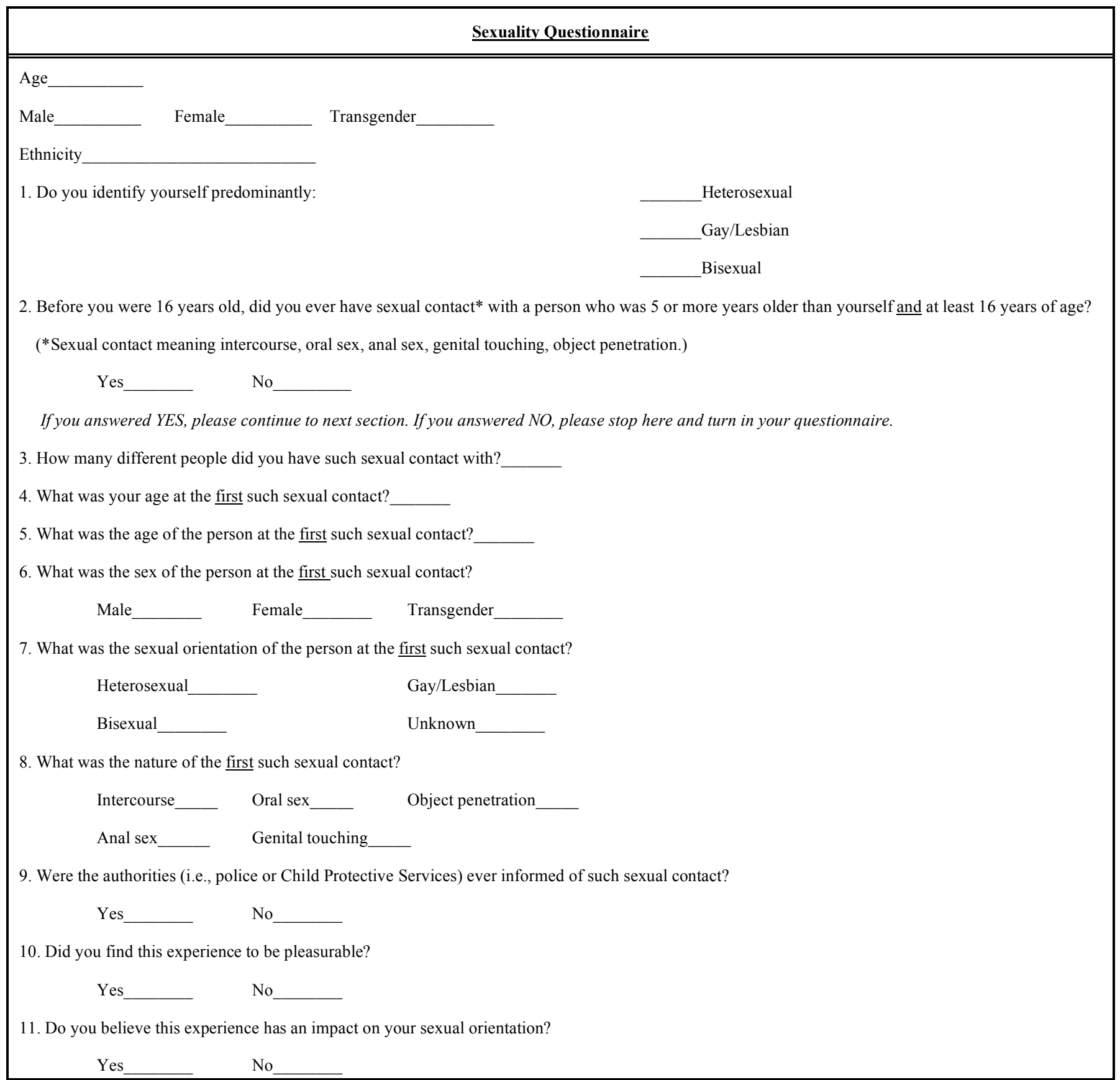

prior to receiving approval to sample individuals at the organization. Once permission was obtained, the primary investigator made arrangements to distribute the questionnaires at the organizations.

All clients at the organization were given the opportunity to complete the questionnaire. No identifying marks were on the questionnaire in order to maintain participants' confidentiality. Consent forms were attached to the distributed questionnaire but did not require the signature of the participant or that it be returned with the questionnaire. Potential participants were informed that completion of the questionnaire constituted consent to participate in the study. Potential participants were informed that their participation was voluntary. Additionally, potential participants were informed that they had the right to not participate or to discontinue participation at any time.

\section{RESULTS}

Table 2 shows the number and percentage of participants who reported molestation. It is apparent that $42(30.7 \%)$ of the 137 males, $59(41.3 \%)$ of the 143 females, and 101 $(36.1 \%)$ of the total number of participants reported molestation. All subsequent tabulations and analyses were performed with only those participants who reported molestation.

Participants reported the number of different people they had such sexual contact with ranged from 1 to 30 , with a 
mean of 4.37 and standard deviation of 5.24. However, two participants did not indicate the number of such sexual contacts, one participant answered with "?" and one participant answered with "lots." These four participants were excluded from the number of different people calculations. Males reported the number of different people they had such sexual contact with ranged from 1 to 30 , with a mean of 6.17 and standard deviation of 6.63 . Thirty-two of the $41(78.0 \%)$ male participants reported having such sexual contact with two or more people. Females reported the number of different people they had such sexual contact with ranged from 1 to 15 , with a mean of 3.05 and standard deviation of 3.43 . Thirty-one of the $56(55.4 \%)$ female participants reported such sexual contact with two or more people.

The age of the participants at the time of first molestation ranged from 3 to 15 , with a mean of 11.11 and standard deviation of 2.74. Males reported age of first molestation ranged from 3 to 15 , with a mean of 11.74 and standard deviation of 2.40. Females reported age at first molestation ranged from 4 to 15 , with a mean of 10.66 and standard deviation of 2.89 .

The gender of the perpetrator at the time of the first molestation was $66(65.3 \%)$ male and $35(37.9 \%)$ female. Males reported $25(37.9 \%)$ male perpetrators and $17(48.6 \%)$ female perpetrators at the time of their first molestation.
Females reported $41(62.1 \%)$ male perpetrators and $18(51.4 \%)$ female perpetrators at the time of their first molestation.

The age of the perpetrator at the time of the first molestation ranged from 16 to 64 , with a mean of 22.75 and standard deviation of 9.28. However, three perpetrators were reported to be an "adult" and two perpetrators' ages were reported as being "unknown." These five perpetrators were excluded from the calculations related to the age of the perpetrator at the time of the first offense. Male perpetrators' ages at first molestation ranged from 16 to 64 , with a mean of 24.37 and standard deviation of 11.13. Female perpetrators' ages at first molestation ranged from 16 to 60 , with a mean of 21.49 and standard deviation of 7.41 .

Table 3 displays the type of sexual act during first molestation for males, females, and the combined participants. The sum exceeds $100 \%$ because of more than one act per molestation. It is apparent that oral sex was most common and object penetration least common.

Table 4 presents the number and percentage of molestations that were reported to authorities. It is apparent that in all four victim/perpetrator categories, the percentage of cases having been reported was low, with the reporting of males molested by females exceptionally low.

Table 2. Frequency and Percentage by Gender and Sexual Orientation of Participants Related to Sexual Contact before Age 16 Years

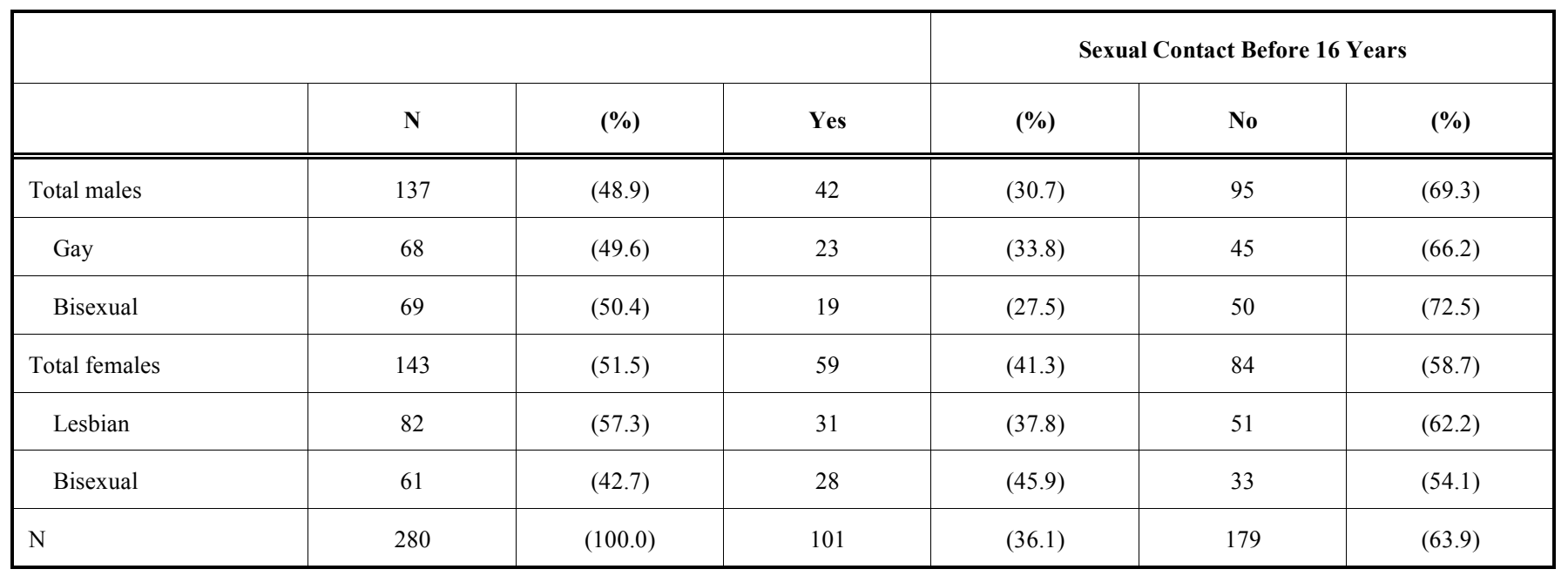

Table 3. Frequency and Percentage by Gender of Participants Molested Related to Sexual Acts Reported During First Molestation

\begin{tabular}{|c|c|c|c|c|c|c|}
\hline Sexual act reported during first molestation: & $\mathbf{N}$ & $\%$ & $\mathbf{N}$ & $\%$ & $\mathbf{N}$ & $\%$ \\
\hline Intercourse & 17 & 40.5 & 10 & 16.9 & 27 & 26.7 \\
\hline Oral sex & 30 & 71.4 & 33 & 55.9 & 63 & 62.4 \\
\hline Anal sex & 15 & 35.7 & 10 & 16.9 & 25 & 24.8 \\
\hline Genital touching & 17 & 40.5 & 26 & 44.1 & 43 & 42.6 \\
\hline
\end{tabular}


Table 4. Frequency and Percentage by Gender of Person Molested and Gender and Perceived Sexual Orientation of Molesting Person Related to Notification of Authorities

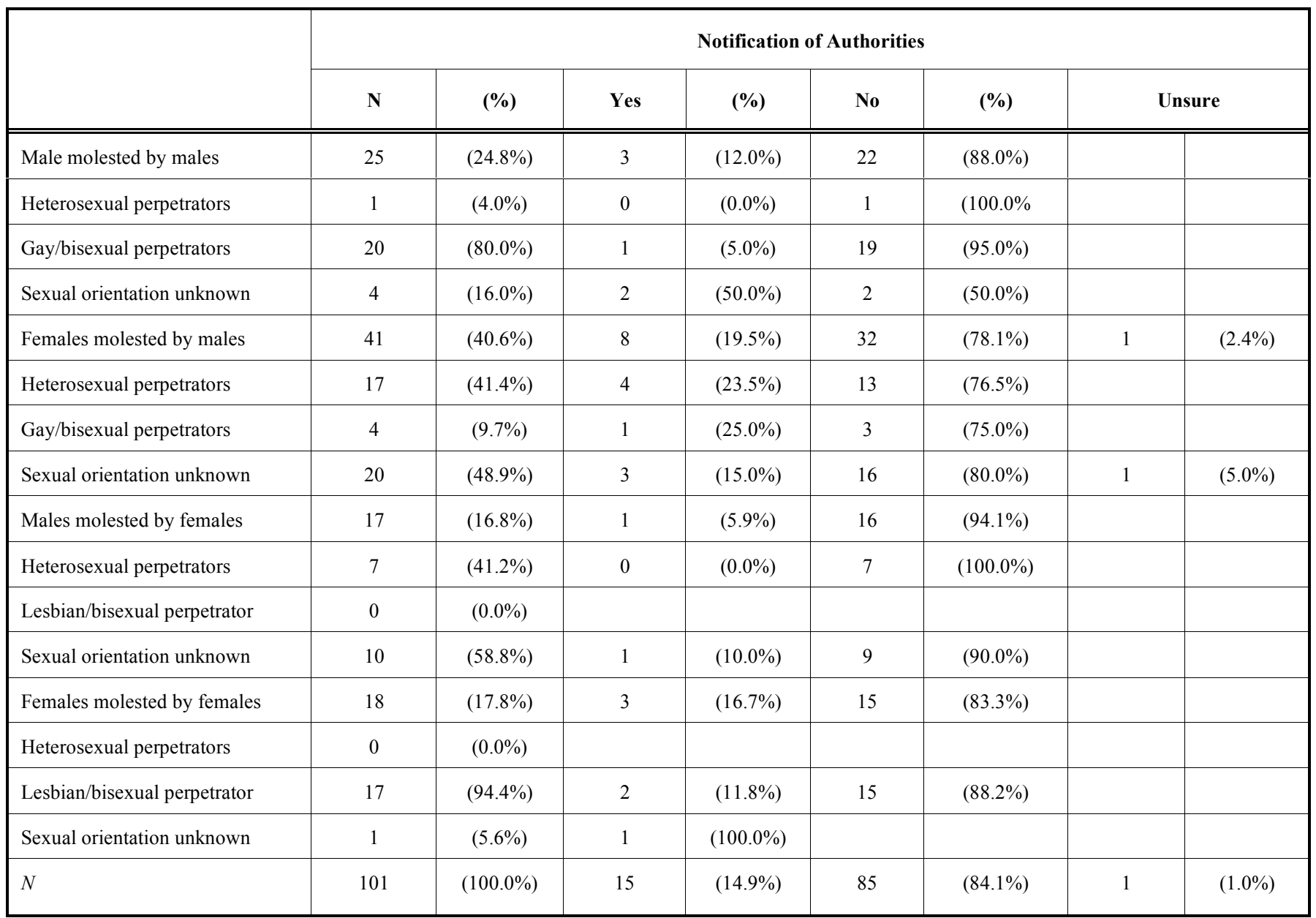

Table 5 presents impact on sexual orientation as a function of the sex of the victim and the sex of the perpetrator. It is apparent that when the molestation was homosexual, the perpetrator was reported as homosexual in the preponderance of cases. Of the male participants who reported homosexual molestation, $80.0 \%$ of the perpetrators were said to be homosexual, $4 \%$ heterosexual, and $16 \%$ of unknown orientation. Of the female participants who reported homosexual molestation, $94.4 \%$ of the perpetrators were said to be homosexual, none heterosexual, and $5.6 \%$ of unknown orientation.

Seventeen $(67.4 \%)$ of the participants who were homosexually molested, in contrast to $26(45.6 \%)$ of those who were heterosexually molested, said the molestation had an impact on their sexual orientation, $\mathrm{X}^{2}(1, \mathrm{~N}=101)=4.72$, $\mathrm{p}<.05$.

Table 6 presents the experience of pleasure as a function of sex and gender of victim and perpetrator. It is apparent that most of the participants reported pleasure. Pleasure was reported in $88.9 \%$ of males molested by females, $88.2 \%$ of males molested by females, $72.0 \%$ of males molested by males, but only $43.9 \%$ of females molested by males. Thirtyfour $(57.49 \%)$ of the 61 victims reported experiencing pleasure with a male perpetrator in contrast to $29(87.9 \%)$ of the 33 victims with a female perpetrator, $\mathrm{X}^{2}(1, \mathrm{~N}=29)=9.17$, $\mathrm{p}<.01$.

\section{DISCUSSION}

For both gay/bisexual men and lesbian/bisexual women, a relatively high percentage reported childhood/adolescent molestation. Fifty-nine (41.3\%) of the 143 female and 42 $(30.7 \%)$ of the male participants reported experiencing childhood/adolescent molestation. Such high rates are consistent with the high rates reported by Tomeo et al. [1] using similar methodology. They found that $22 \%$ of the lesbians and $46 \%$ of the gay men reported molestation. A high rate of molestation of homosexual persons has also been reported by other authors $[2-4,11,12]$.

The low rate of reporting molestation to authorities is not a striking finding because such a low rate of reporting is almost invariably found in the molestation literature. The very low rate, only one case, in males molested by females, meshes with the below-referred-to study of Condy et al. [13] in which boys molested by women tended to regard it as a positive experience.

A salient finding is that $80.0 \%$ of the males who were molested by males regarded the perpetrators' sexual orientation as being gay or bisexual, and $94.4 \%$ of the females who were molested by females regarded the perpetrators' sexual orientation as being lesbian or bisexual. A caution about the present finding is that it is possible that the participants 
Table 5. Frequency and Percentage by Gender of Person Molested and Gender and Perceived Sexual Orientation of Molesting Person Related to Impact on Sexual Orientation

\begin{tabular}{|c|c|c|c|c|c|c|c|c|c|c|}
\hline & $\mathbf{N}$ & $(\%)$ & Yes & $(\%)$ & No & $(\%)$ & Un-sure & $(\%)$ & Did not answer & $(\%)$ \\
\hline Males molested by males & 25 & $(24.8 \%)$ & 17 & $(68.0 \%)$ & 7 & $(28.0 \%)$ & & & 1 & $(4.0 \%)$ \\
\hline Heterosexual perpetrators & 1 & $(4.0 \%)$ & 1 & $(100.0 \%)$ & & & & & & \\
\hline Sexual orientation unknown & 4 & $(16.0 \%)$ & 2 & $(50.0 \%)$ & & & & & & \\
\hline Females molested by males & 41 & $(40.0 \%)$ & 17 & $(41.5 \%)$ & 23 & $(56.1 \%)$ & 1 & $(2.4 \%)$ & & \\
\hline Heterosexual perpetrators & 17 & $(41.4 \%)$ & 9 & $(52.9 \%)$ & 8 & $(47.1 \%)$ & & & & \\
\hline Gay/bisexual perpetrators & 4 & $(9.7 \%)$ & 2 & $(50.0 \%)$ & & & & & & \\
\hline Heterosexual perpetrators & 7 & $(41.2 \%)$ & 3 & $(42.9 \%)$ & 4 & $(57.1 \%)$ & & & & \\
\hline Lesbian/bisexual perpetrators & 0 & $(0.0 \%)$ & & & & & & & & \\
\hline Sexual orientation unknown & 10 & $(58.8 \%)$ & 6 & $(60.0 \%)$ & 4 & $(40.0 \%)$ & & & & \\
\hline Females molested by females & 18 & $(17.8 \%)$ & 12 & $(66.7 \%)$ & 4 & $(22.2 \%)$ & 2 & $(11.1 \%)$ & & \\
\hline Heterosexual perpetrators & 0 & $(0.0 \%)$ & & & & & & & & \\
\hline Lesbian/bisexual perpetrators & 17 & $(94.4 \%)$ & 12 & $(70.6 \%)$ & 3 & $(17.6 \%)$ & 2 & $(11.8 \%)$ & & \\
\hline Sexual orientation unknown & 1 & $(5.6 \%)$ & 0 & $(0.0 \%)$ & 1 & $(100.0 \%)$ & & & & \\
\hline
\end{tabular}

assumed the sexual orientation of the perpetrator to be gay, lesbian, or bisexual due to the molestation being homosexual in nature. On the other hand, the participants did have the option of reporting the sexual orientation of the perpetrator as being unknown.

The fact that a majority of molested lesbian/bisexual women $(57.6 \%)$ and gay/bisexual men $(78.6 \%)$ in the study found the experience to be pleasurable is consistent with the meta-analysis of Rind, Tromovitch, and Bauserman [11], which concluded that most molested children or adolescents do not regard the experience as highly traumatic. This, of course, should not be interpreted as meaning that molestations should usually be regarded as an inconsequential event. Furthermore, less than half $(48.9 \%)$ of females molested by males in the present study did not regard the experience to be pleasurable. The male and female participants in this study were more likely to regard the experience as pleasurable (88.2\% and $89.9 \%$, respectively) if the perpetrator of the abuse was female. This is consistent with the study of Condy et al. [4] where adult males reported past molestation by older females to be a positive experience. However, it should be pointed out that the adult males who reported childhood molestation in the Condy et al. [4] study reported the experience to be traumatic if force was used or if the molester was a close relative, such as the mother. It is possible that in the present study the female participants did not regard the mo- lestation by male perpetrators as pleasurable due to coercion or incest.

Perhaps the most salient finding is that $68.0 \%$ of the gay men and $66.7 \%$ of the lesbian women who had been homosexually molested maintained it had an impact on their sexual orientation. Although it is an important finding, it is not known what various participants meant by "impact." The most provocative possibility is that the participants would not have become homosexual if it were not for the molestation. A related possibility is that the molestation facilitated or accelerated or strengthened an already emerging homosexual orientation. Another possibility is that the molestation produced some sort of negative cognitive and/or emotional component in their identity as a homosexual. It should be borne in mind that $52.9 \%$ of the men and $41.5 \%$ of the women reported impact from heterosexual molestation. Perhaps the early sexual experience kindled sexual awareness and made them open to a variety of sexual experiences. It is well established that molestation can bring about hypersexuality in children. The reader is urged to use great caution regarding the making of cause-and-effect inferences.

It is recommended that future research not only ask about impact on sexual orientation but the specific impact and possible mechanisms. A research design that includes a semistructured interview may be useful. 
Table 6. Frequency and Percentage by Gender of Person Molested and Gender and Perceived Sexual Orientation of Molesting Person Related to Experience of Pleasure

\begin{tabular}{|c|c|c|c|c|c|c|c|c|}
\hline & Yes & $(\%)$ & No & $(\%)$ & Unsure & $(\%)$ & Did Not Answer & $(\%)$ \\
\hline Males molested by males & 18 & $(72.0 \%)$ & 7 & $(28.0 \%)$ & & & & \\
\hline Heterosexual perpetrators & 1 & $(100.0 \%)$ & & & & & & \\
\hline Sexual orientation unknown & 2 & $(50.0 \%)$ & 2 & $(50.0 \%)$ & & & & \\
\hline Females molested by males & 18 & $(43.9 \%)$ & 20 & $(48.9 \%)$ & 2 & $(4.9 \%)$ & 1 & $(2.3 \%)$ \\
\hline Heterosexual perpetrators & 7 & $(41.2 \%)$ & 9 & $(52.9 \%)$ & 1 & $(5.9 \%)$ & & \\
\hline Gay/bisexual perpetrators & 3 & $(75.0 \%)$ & 1 & $(25.0 \%)$ & & & & \\
\hline Heterosexual perpetrators & 7 & $(100.0 \%)$ & & & & & & \\
\hline \multicolumn{9}{|l|}{ Lesbian/bisexual perpetrators } \\
\hline Sexual orientation unknown & 8 & $(80.0 \%)$ & 2 & $(20.0 \%)$ & & & & \\
\hline Females molested by females & 16 & $(88.9 \%)$ & 2 & $(11.1 \%)$ & & & & \\
\hline \multicolumn{9}{|l|}{ Heterosexual perpetrators } \\
\hline Lesbian/bisexual perpetrators & 15 & $(88.2 \%)$ & 2 & $(11.8 \%)$ & & & & \\
\hline Sexual orientation unknown & 1 & $(100.0 \%)$ & & & & & & \\
\hline
\end{tabular}

\section{CONCLUSION}

The majority of gay men and lesbians who had been homosexually molested reported that this molestation had an impact on their sexual orientation. Caution regarding inferences is recommended.

\section{REFERENCES}

[1] Tomeo ME, Templer D, Anderson S, Kotler D. Comparative data of childhood and adolescence molestation in heterosexual and homosexual persons. Arch Sex Behav 2001; 30: 535-41.

[2] Bradford J, Ryan C, Rothblum E. National lesbian health care survey: Implications for mental health care. Ann Consult Clin Psychol 1994; 62: 228-42.

[3] Cameron P, Cameron K. Does incest cause homosexuality? Psychol Rep 1995; 76: 611-21.

[4] Doll LS, Joy D, Bartholow BN, et al. Self-reported childhood and adolescent sexual abuse among adult male homosexual and bisexual men. Child Abuse Neglect 1992; 16: 855-64.

[5] Harry J. A probability sample of gay males. J Homosexual 1990; 19(1): 89-104.
[6] Hewitt C. Homosexuality demography: Implications for the spread of AIDS. J Sex Res 1998; 35: 390-96.

[7] Bell AP, Weinberg MS. Homosexualities: A study of diversity among men and women. New York: Simon \& Schuster 1978.

[8] Davis DL, Whitten RG. The cross-cultural study of human sexuality. Annu Rev Anthropol 1987; 16: 69-98.

[9] Seawyc E, Bearinger L, Blum R, Resnick M. Sexual intercourse, abuse and pregnancy among adolescent women: Does sexual orientation make a difference? Fam Plann Perspect 1999; 31: 12731.

[10] Whitman FL, Daskalos C, Soboleswski CG, Padilla P. The emergence of lesbian sexuality and identity cross-culturally: Brazil, Peru, the Philippines, and the United States. Arch Sex Behav 1998; 17(1): 31-56.

[11] Hall JM. Pervasive effects of childhood sexual abuse in lesbians recovery from alcohol problems. Subst Use Misuse 1996; 31: 22539.

[12] Simari CG, Baskin D. Incestuous experiences within homosexual population: A preliminary study. Arch Sex Behav 1982; 11: 32944.

[13] Condy SR, Templer DI, Brown R, Veaco L. Parameters of sexual contact of boys with women. Arch Sex Behav 1987; 16: 37994. 